\title{
SIGNALING ACTIVATED BY THE DEATH RECEPTORS OF THE TNFR FAMILY
}

\author{
Ladislav Andera
}

Institute of Molecular Genetics AS CR, Videnska 1083, 14220 Prague 4, Czech Republic

e-mail:andera@img.cas.cz

Received: August 25, 2009; Accepted: September 16, 2009

Keywords: Caspases/Necroptosis/Apoptosis/DISC/Death domain

Background: The fine balance in cellular life and death is affected by a number of tightly regulated, direct signals that can help to turn the balance either in favor of or against the ultimate fate. Among the most prominent players in the field of the extracellular signals leading to cell death, preferentially through induction of apoptosis belong several receptors from so-called Death Receptors group of the Tumour Necrosis Factors Receptors (TNFR) family.

Methods and results: Over 15 years of the research on activation and regulation of the most prominent member of this group - receptors for the ligands TRAIL, FasL and TNF $\alpha$ brought not only a detail (and still refining) mechanism of these receptors activation and downstream signaling, but also connected them with the ultimate apoptotic gatekeeper - mitochondria. Mitochondria are, in addition to their essential role as the energy factories also repositories of a cavalry of apoptosis-inducing as well as regulatory proteins. However, in addition to the pro-death signaling, these receptors were also shown under certain circumstances to activate an opposite, pro-proliferative signaling as well as to participate in pro-inflammatory responses.

Conclusions: Thus despite the concerned effort of a number of groups and thousands of published papers, novel roles for the intriguing group of these receptors and their ligands and fine tuning of their signaling still await to be uncovered. This cut-through review will be mainly focused on the prominent death-inducing members of this group TNFR1, Fas/CD95 and TRAIL receptors.

\section{INTRODUCTION}

The receptors from the TNFR family upon their activation by corresponding ligand trigger a number of signaling pathways that regulate diverse biological functions as proliferation, differentiation and also apoptosis ${ }^{1,2}$. Their common feature of these receptors is the presence of specific structural unit(-s) in their extracellular parts called the cysteine-rich domain (CRD). These approximately 40 amino acids long pseudorepeats contain three disulfide bridges and their interconnecting loops are usually interaction places for their binding to corresponding ligands. A specific group of eight receptors within the TNFR family can be distinguished by the presence of a a-helical protein-protein interaction domain named the Death Domain (DD) ${ }^{3}$. This bundle of six anti-parallel a-helices is an essential platform e.g. for the formation of the Death-Inducing Signaling Complex (DISC), a multiprotein complex required for the proximity-based processing and activation of the initiator caspases- 8 and -10. Among the death receptors are both true killers and casual murderers. The killer ones are Fas/CD95 and death domain-containing TRAIL receptors TRAIL-R1/DR4 and TRAIL-R2/DR5. To the later ones belong TNFR1, DR3, DR6, EDAR and NGFR, though EDAR and NGFR upon binding their respective ligands mainly activate signaling pathways connected proliferation, survival and/or differentiation. But even both true killer receptors as Fas/CD95 and DR4/5 receptors can under certain circumstances activate pro-survival and proliferation-related signaling pathways.

\section{TNFR1 - the founding member and a prototypic death receptor}

The ligand for TNFR1 receptor (CD120a; p55/60) - Tumour Necrosis Factor (TNF, also known as TNFa) was identified in 1975 as an agent that caused haemorrhagic necrosis of in mice transplanted sarcomas and later cloned and characterized ${ }^{4,5}$. TNF is expressed as a type II trimeric transmembrane protein, which could be cleaved of by the metalloprotease TNF alpha converting enzyme (TACE) $)^{6,7}$. Both soluble and membrane-bound TNF $\alpha$ upon binding to the cognate receptors TNFR1 (CD120a; p55/60) and TNFR2 (CD120b; p75/80) induce in cellspecific manner pro-survival and pro-inflammatory signaling or cell death. TNFR1 in its extracellular part contains 4 CRDs and the N-terminal Pre-ligand assembly domain (PLAD), which allows formation of pre-assembled receptors at the cell surface ${ }^{8}$. This PLAD domain is also present in other Death receptors as TRAIL-R2 and enhances ligand-mediated activation of these receptors ${ }^{9}$. TNFR 1 is widely expressed on most cell types while TNFR2 expression is restricted to hematopoetic cells. As TNFR2 does not contain the death domain, I shall further on focus on TNFR1-triggered signaling and its outcome.

Upon the engagement of either soluble or membranebound TNF $\alpha$ the first TNFR1 signaling complex I is rapidly formed. Its formation and consecutive activation of downstream signaling is greatly enhanced by TNFR1 localization/recruitment to cholesterol- and sphingolipidenriched membrane microdomains, termed lipid rafts ${ }^{10,11}$. TNF $\alpha$-induced allosteric changes in the intracellular part of TNFR1 attract a number of adapter proteins and en- 


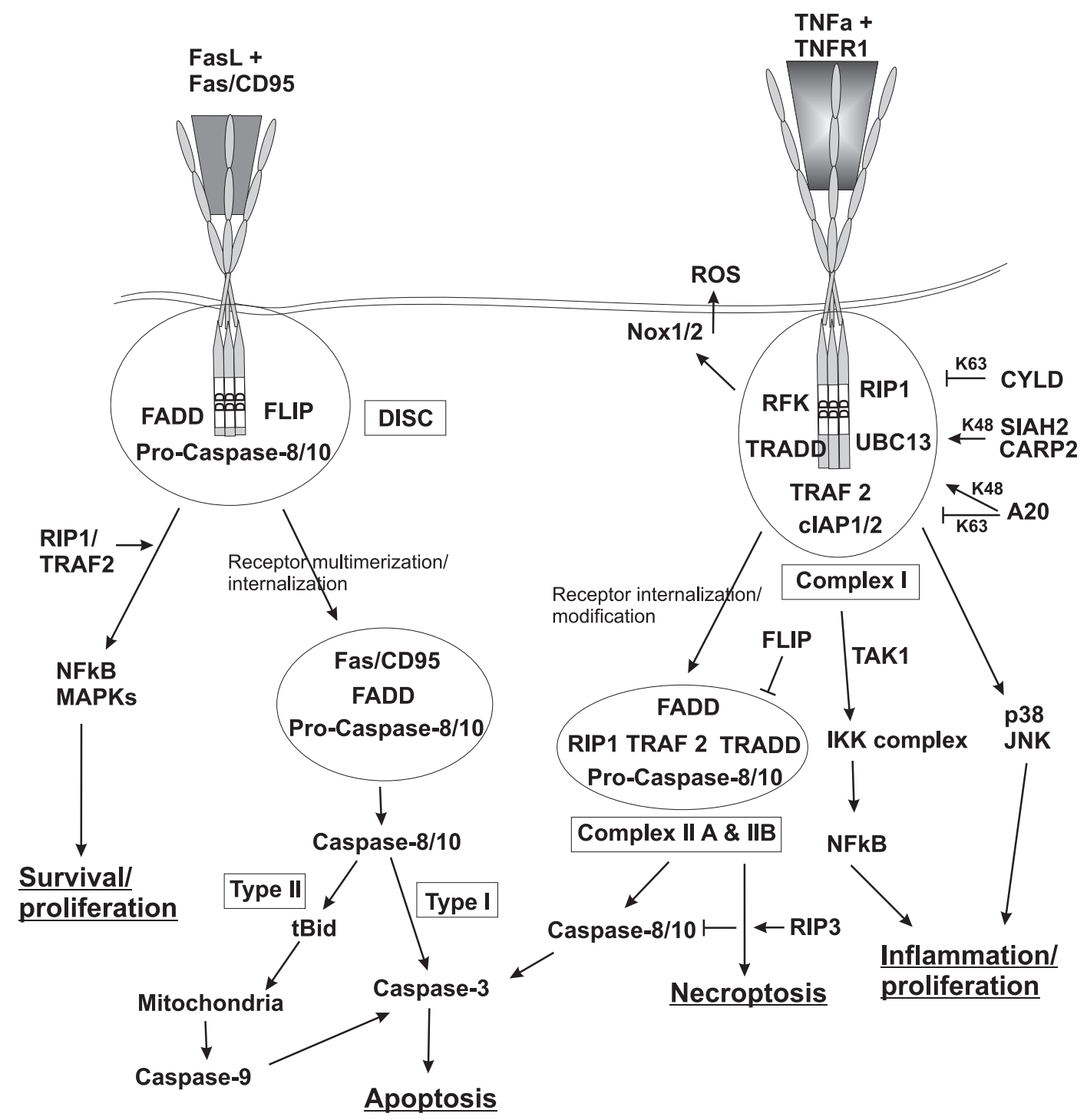

Fig. 1. Prototypic death receptors signaling pathways.

Fas/CD95 and TNFR1 upon activation by their cognate ligands multimerize and re-arrange their intracellular parts to form platforms for the formation of multiprotein signaling complexes. TNFR1 signaling complex I is composed of the adapter proteins TRADD, TRAF 2, DD-containing RIP1 kinase and several other associated proteins as cIAP1/2 and E2 protein UBC13. TRAF2 E3 ligase in the complex I then ubiquitinates RIP1 via signaling-related K63 polyubiquitinilation and modified RIP1 then both directly and indirectly (via TAK1 kinase) activates (via IKK kinase complex) phosphorylation and subsequent degradation of IkB and thus activation of NFkB signaling. Complex I activity is negatively regulated by E3 ubiquitin ligases SIAH2, CARP2 and A20 (dual ubiquitin ligase and hydrolase) that target TRAF2 and RIP1 for degradation and by ubiquitin hydrolases CYLD and A20, which remove the signaling K63-linked ubiquitins. Complex I participates also in activation of MAP kinases via yet not fully decrypted pathway and via with TNFR1 DD-interacting riboflavin kinase (RFK) also enhances NADPH oxidase (Nox1/2)-activated production of reactive oxygen species (ROS). Upon internalization of the activated TNFR1 the secondary intracellular complexes IIA (RIP1/ FADD/pro-caspase-8) and IIB (TRADD/FADD/ pro-caspase-8) could be formed with the participation of the adapter protein FADD and pro-caspase-8. In these complexes is caspase-8 activated and overexpression of the competitive inhibitor FLIP predominantly suppresses its activation in complex IIB. Upon inhibition of caspases, secondary RIP3-containing and necroptosis-activating complexes are established. In contrast to TNFR1 signaling, the default pathway activated by Fas/CD95 or TRAIL receptors is caspase-8 activation in DISC and induction of apoptosis. Efficient induction of the death signaling requires receptor clustering in lipid rafts and is enhanced upon internalization. Efficacy of caspase-8 activation and the presence of intracellular caspase inhibitors as XIAP then divide cells into two types - in type I, mitochondria-independent and on mitochondrial amplification of the apoptotic signaling-relying, type II cells. Similarly as TNFR1, under the conditions of suppressed apoptosis, Fas/CD95 induce NFkB and MAPK activation in a not fully understood, RIP1 and TRAF2-dependent mechanism. 
zymes into the cytoplasmic membrane-associated complex I (Fig.1). Death domain-containing adapter proteins TRADD and RIP1 kinase form seeding ground for association of several ubiquitin E3 ligases, notably a RING domain-containing TRAF2 (or TRAF5) and cIAP1/2 together with E2 ubiquitin conjugating protein UBC13. Both of the adapter proteins are quazi-essential for the progression of TNF $\alpha$-triggered signaling in the complex I.

Ubiquitination of a number of proteins in the complex I plays an important role in the signal transduction in both negative and positive ways and thus it is no wonder that a number of other ubiquitin E3 ligases and hydrolases is associated with and regulates activity of the complex I (reviewed in ref. ${ }^{12,13}$ ). Both TRAFs $2 / 5$ and cIAPs participate in ubiquitination of RIP1, TRAF2 and also TNFR1 via ubiquitin chains linked through lysine 63 (K63) ${ }^{14-16}$ TRAF2 and combined cIAP1/2 deficiency were shown to abrogate signaling from complex I and sensitize cells from TRAF2 and cIAP1/2 knockout mice to TNF $\alpha$-mediated apoptosis $^{15-18}$. K63-linked ubiquitination of RIP1 at K377 is essential for the recruitment and activation of two downstream signaling complexes - the IKK and TAK1 kinases. Polyubiquitinated RIP1 directly recruits IKK complex via the IKK regulatory subunit NEMO and activates IKK $\alpha$ and $\beta$ kinases in the complex ${ }^{19,20}$. An alternative indirect route brings the TAK 1 complex via its TAB $2 / 3$ regulatory, ubiquitin-binding subunits and triggers thus allosteric activation of TAK1 (ref. ${ }^{21}$ ). Activated TAK1 then phosphorylates and activates the IKK complex. The activated IkKs then phosphorylates IkBs proteins in the NFkB/ IkB cytosolic complex and marks them for ubiquitination by SCFbTrCP E3 ligase and degradation in the proteasome (reviewed in ref. ${ }^{22}$ ). Degradation of IkB proteins releases NFkB heterodimer, which then translocates to the nucleus and activates expression of a number of proinflammatory, anti-apoptotic and also regulatory genes (as A20 or CYLD, see below).

This, so-called canonical pathway of NFkB activation poses a severe implication on the organism and thus needs to be tightly regulated. Similarly as in the activation the complex I-mediated signaling, also in its suppression protein ubiquitination plays an important role. Several E3 ligases and ubiquitin hydrolases compete in shutting down this canonical signaling at the level of the signaling complex I. At least four different proteins were shown to affect ubiquitination of two major constituents of the complex I - RIP1 and TRAF2 (Fig. 1). A20 dual E3 ligase and ubiquitin hydrolase was about 10 years ago identified as a critical regulator of $\mathrm{TNF} \alpha$ mediated activation of $\mathrm{NFkB}^{23}$. A20 via its ubiquitin hydrolase domain cleaves off activating scaffold K63-linked polyubiquitin chain from RIP1 and subsequently marks RIP1 for proteasomal degradation through its K48-linked polyubiquitination. A20 is also transactivated by $\mathrm{NFkB}$ a thus serves as a negative feedback to limit potentially harmful TNF $\alpha$-induced pro-inflammatory activation of NFkB. A20 activity is enhanced through its interaction with TaxP1, a binding protein of the hTLV Tax protein, its associated E3 ligase Itch a recently also via another interacting protein RFN11 (ref. ${ }^{2426}$ ). Another two K-48- linking E3 ligases SIAH2 and CARP2 also participate in fine tuning of the NFkB activation pathway. SIAH2 in addition to enhancing the hypoxia response also targets TRAF2 to degradation, thus attenuating activation of $\mathrm{NFkB}^{27,28}$. CARP2 was together with CARP1 identified as Caspase-8-Associated Ring Protein and was reported to attenuate $\mathrm{TNF} \alpha$-induced apoptosis via marking caspase- 8 for degradation ${ }^{29}$. It was also recently shown to localize to endosomes and target RIP1 for degradation ${ }^{30}$. In addition to E3 ligases another ubiquitin hydrolase and tumor suppressor - cylindrimatosis (CYLD) negatively influences activation of $\mathrm{NFkB}$ via removing the activating K63-linked ubiquitin chain from TRAF2 and is also, similarly as A20, activated by NFkB as a part of autoregulatory feedback loop ${ }^{31-33}$.

Blocking the NFkB-activating pathway e.g. by suppressing RIP1 ubiquitination shifts a signaling outcome more towards induction of cell death. For TNF $\alpha$-triggered apoptosis is required endocytosis of the complex I. Then depending on situation several possible cell death-activating complexes II can be formed. Micheau and Tschopp and later Wang et al. documented that TRADD and RIP1 are released from the complex I and form a seeding ground for two cytoplasmic caspase-8-activating complexes IIA (TRADD/FADD/Procaspase-8) and IIB (FADD/ RIP1/Pro-caspase-8) containing in addition adapter protein FADD and pro-caspase- 8 ( ref. $^{34,35}$ ). However, there is discrepancy when and whether at all these cytoplasmic complexes are formed. In other reports complex II is formed upon RIP1 degradation on internalized TNFR1 endosomes (reviewed in ref. ${ }^{36}$ ). Activation of TNF $\alpha$ induced apoptosis, i.e. formation of the pro-apoptotic complexes II is enhanced by knockout or inactivation of the complex I-activating components RIP1, TRAF2 or cIAPs $1 / 2$.

When apoptosis is blocked by suppressing activity of caspases either by endogenous (XIAP) or exogenous caspase inhibitors (e.g. pan-caspase inhibitor zVADfmk or viral proteins as 13R/Spi2 from vaccinia virus) then RIP1dependent death so called necroptosis can be activated ${ }^{37,38}$. Essential role of RIP1 kinase activity in the induction of necroptosis was confirmed by blocking necroptosis by necrostatin-1, a specific inhibitor of RIP kinases ${ }^{39,40}$. From the screening for factors required for necroptosis turned out that in addition to RIP1 also CYLD, BH3-only protein Bmf and other proteins are probably also required ${ }^{41}$. Till recently was still a mystery how exactly can RIP1 activate this necrotic mode of cell death. Apparently the activity of another member of RIP kinase family - RIP3 was also required in this process ${ }^{42}$. Recent discoveries from 3 groups now bring at least some light to deciphering this necrotic pathway ${ }^{38,43,44}$. They all document that RIP3 kinase (in addition to RIP1) is essential for the activation of TNFa-induced necroptosis. Both complexes IIA and IIB could upon RIP3 binding, and when caspase-dependent apoptotic pathway is blocked, transit from the pro-apoptotic to the pro-necrotic signaling. RIP3 kinase activity is essential for this transition and blocking its activity with necrostatin-1 suppresses interaction between RIP1/3 and FADD as well as RIP1-RIP3 association. FADD seems 
to be important but not entirely essential for RIP1/3 phosphorylation activity as RIP1 phosphorylation still takes place in FADD-deficient Jurkat cells ${ }^{38}$. One of the necrotic death tools are also ROS that are required for TNF $\alpha$-activated necroptosis in L929 cells ${ }^{37}$. Interestingly RIP3 in the necroptosis-activating complexes interacts with several enzymes that could affect production of ROS, namely with glycogen phosphorylase (PYGL), glutamate ammonia ligase (GLUL), and glutamate dehydrogenase

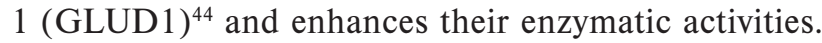
These and other identified metabolism-related enzymes indirectly affect oxidative phosphorylation in mitochondria and thus also the production of mitochondrial ROS. Their siRNA-mediated knockdown partially protected NIH3T3 cells against $\mathrm{TNF} \alpha / \mathrm{zVAD}$-induced necroptosis. However, they seems to be just hijacked by the necroptosis apparatus as their physiological function (similarly as that of RIP3) is to provide energy to cells that underwent through some toxic insult or injury.

The fate of the first death receptor underwent an interesting evolution from its discovery about 30 years ago - from mainly pro-inflammatory to apoptosis-inducing receptor with recently the circle closing and TNFR1 stands its true name as under specific circumstances the necrosis or better necroptosis-inducing one.

\section{The deadly siblings - Fas/CD95 and TRAIL receptors}

Receptors for the cytotoxic ligands FasL and TRAIL were discovered in the last decade of the past century either as targets of apoptosis-inducing monoclonal antibodies (Fas/CD95) or similarly as the TRAIL ligand by computer-aided cloning (TRAIL-Rs) ${ }^{45-48}$. In addition to two pro-apoptotic, death domain-containing TRAIL receptors TRAIL-R1/DR4 and TRAIL-R2/DR5 were in human cells discovered three additional so-called decoy receptors, membrane-bound TRAIL-R3/DcR1, TRAIL-R4/DcR2 and soluble osteoprotegerin. Similar decoy, inhibitory receptor DcR3 was also identified for the FasL ${ }^{49}$. When overexpressed, these decoy receptors suppress signaling, mainly induction of apoptosis, from the DD-containing receptors. Fas/CD95 and DD-containing TRAIL receptors are expressed on majority of normal cells but their ligands are under normal conditions expressed on hematopoietic cells (mainly T lymphocytes and NK cells).

Upon activation with the membrane-bound (FasL, TRAIL) or soluble (agonistic antibodies, recombinant TRAIL or recombinant and multimerized FasL) ligands the DD-containg receptors are trimerized/multimerized and form an accepting platform for binding the additional components of DISC - the adapter protein FADD and pro-caspases-8/10 (reviewed in ref. ${ }^{36,50}$ ). In a sharp contrast to TNFR1-activated signaling, the activated Fas/CD95 or TRAIL receptors predominantly activate apoptosis and not the inflammatory response via NFkB activation. Through homotypic aggregation in DISC, enhanced by low levels of the inactive $\mathrm{CFLIP}_{\mathrm{L}}$, originally a competitive inhibitor of caspase- 8 activation, caspase- 8 is gradually activated and released into cytosol, where it cleaves its target proteins, most notably the pro-apoptotic, BH3-only pro- tein $\mathrm{Bid}^{51}$. In contrast to TRAIL receptors, which could be apparently fully activated at the cytoplasmic membrane, efficient activation of Fas/CD95 DISC and subsequently caspase- 8 requires receptor internalization via mainly clathrin-dependent endocytosis ${ }^{36,52,53}$. Furthermore and also in a contrast to TNFR1, postranslational modifications of these receptors such as S-linked palmitoylation of membrane-proximal cysteines or O-linked glycosylation of the extracellular parts of TRAIL receptors enhance their aggregation, mainly in lipid rafts, and subsequently the efficacy of the DISC activation and caspase- 8 selfprocessing $^{52-55}$.

More or less efficient activation of the initiator caspase- 8 and the presence (or absence) of intracellular inhibitors of apoptosis from the Bcl-2 or IAP families then sends affected cell to so-called type I or type II of the apoptotic signaling ${ }^{56-59}$. An essential transducer of the apoptotic signaling in type II cells as hepatocytes is the $\mathrm{BH} 3$-only protein $\mathrm{Bid}^{60}$. Activated caspase- 8 cleavesoff N-terminal part of Bid, allowing it then to undergo $\mathrm{N}$-terminal myristoylation together with unmasking of its BH3 domain and then its efficient transport to mitochondria ${ }^{61}$. In mitochondria the activated Bid can both target and inactivate anti-apoptotic Bcl-2, such as Bcl-2 itself, $\mathrm{Bcl}_{\mathrm{L}}$ or $\mathrm{Mcl1}$, as well as directly interact with the pro-apoptotic Bax or Bak proteins and accelerate thus their oligomerization a formation of channels in the outer mitochondrial membrane ${ }^{62-65}$. Permeabilized mitochondria then release a cavalry of pro-apoptotic proteins from cristae and the inter-membrane space such as cytochrome c, endonucleases AIF and endoG as well as Smac/DIABLO and HrtA2/Omi, competitive inhibitors of anti-apoptotic proteins from the IAP family (reviewed in ref. ${ }^{66}$ ). Concerned action of these proteins ensures amplification of the apoptotic signal and dooms a fate of the affected cells. Interestingly an alternative way of caspase- 8 activation in Fas-induced apoptosis of type II cells was recently proposed by Gonzalves et al. ${ }^{67}$. In this scenario a mitochondria-specific phospholipid cardiolipin serves as a platform for full processing and activation of caspase-8.

Both FasL- and TRAIL-induced apoptosis are important effectors as well as regulators of the immune system $^{68,69}$. Fas-mediated killing is together with granzyme/ perforin system used by the cytotoxic $\mathrm{T}$ cells for both elimination of target e.g. damaged or transforming cells as well as, together with BH3-only protein Bim-induced apoptosis, for maintaining of $\mathrm{T}$ cell homeostasis ${ }^{70}$. Also TRAIL-mediated apoptosis is implicated both in NK cells-mediated killing of tumor, preferentially metastatic cells and in the maintenance of the immune system through TRAIL-induced elimination of "helpless" CD8+ T cells ${ }^{71,72}$. In addition to the induction of apoptosis both Fas/CD95 and TRAIL receptors have been under certain circumstance implicated in activation of non-apoptotic signaling mediated via NFkB and MAP kinases pathways as well as, similarly as TNFR1, in inducing a necrosis-like mode of death. RIP1 kinase and the caspase- 8 competitive inhibitor FLIP ${ }_{\mathrm{L}}$ are implicated in the formation secondary cytoplasmic complexes that transduce both necrotic and 
pro-survival signaling ${ }^{3,73}$. Interestingly, Fas/CD95 stimulation on the native $\mathrm{T}$ cells neither induces apoptosis (in a contrast to activated T cells), nor pro-survival pathways but efficiently suppresses their proliferation through yet undefined mechanism that prevents translocation of important signaling proteins as ZAP-70 or phospholipase $\gamma$ into lipid rafts ${ }^{74}$.

In addition to its physiological role, TRAIL-induced signaling could one of the important tools in our fight against cancer. Unique feature of TRAIL-induced apoptosis is its prevalence against transformed cells while sparing the normal ones ${ }^{75}$. Both the recombinant ligand and the agonistic anti-DR4 or DR5 humanized monoclonal antibodies are currently in phase I/II of clinical trials as mono- ore combi-therapeutics against many types of tu$\operatorname{mors}^{76,77}$.

\section{Other members of the death domain group - ambiguous receptors with the death domain}

In contrast the founding member of this family, TNFR1 and two fundamentally pro-apoptotic FasL- or TRAIL-induced signaling, other receptors from the DD group have more diverge functions.

EDAR (ectodysplasin A receptor) was cloned by positional cloning of gene/-s mutated in downless (dl) mice that suffer with defects in hair follicles, lack sweat glands and have malformed teeth ${ }^{78}$. Defects in EDAR signaling are manifested in a rare and life-threatening human disorder X-linked hypohidrotic diaplasia caused by mutations in Eda gene on X chromosome. At least in mice this phenotype can be cured by the treatment of pregnant mice with the recombinant ligand EDA1 (ref. ${ }^{79}$ ). Despite its death domain, ligation of EDAR with EDA1 does not induce apoptosis, but via a novel death domain-containing adapter crinkled (CR) it activates canonical NFkB signaling pathway regulated by already mentioned ubiquitin hydrolase cylidrimatosis ${ }^{80,81}$.

Widely expressed NGF receptor or p75 neurotrophin receptor possesses so-called type II death domain apparently different from the other members of the death domain subfamily. Also, in addition to NGF, NGFR interacts with other ligands as BDNF or neurotrophins. Activated NGFR heterodimerizes with TrkA co-receptor and via triggering a number of signaling pathways (MAP kinases, PI-3 kinase and NFkB) grants neuronal proliferation and survival (reviewed in ref. ${ }^{82,83}$ ). Similarly as other death receptors, NGFR can also transduce cell death signaling under certain conditions. When activated either by BDNF or neurotrophins without co-stimulatory signaling from TrkA, NGFR can via enhanced ceramide production and activation of JNK and p38 MAPK pathways trigger apoptosis in oligodendrocytes or in stressed hippocampal neurons ${ }^{84,85}$.

Another two death domain-containing receptors Death Receptor 3 (DR3) and Death Receptor 6 (DR6) were originally identified by homology cloning and for a long time remained as orphan receptors ${ }^{86,87}$. Both of them also upon transient overexpression induced weak apoptosis in some tumor-derived cell lines through yet undefined mechanism, but their main signaling proceeds via activation of NFkB and MAP kinases (mainly JNK and $\mathrm{p} 38$ ) transduction pathways. TL1A (TNF-like factor 1) was then identified as the major DR3 ligand and via NFkB activation functions as T cell activation co-stimulator $^{88}$. DR3 has a prominent role in the regulation of the immune system as it contributes to efficient $\mathrm{T}$ cell activation, mainly during inflammatory response ${ }^{89,90}$. However, in non-hematopoiteic cells DR3 apparently plays also an active role in the development of antigen-induced arthritis (AIA) and contributes to human renal tubular epithelial cells (TEC) destruction in response to injury ${ }^{91,92}$.

DR6, another highly glycosylated ${ }^{93}$ and till this year an orphan receptor is expressed both on hematopoietic and neuronal cells. Phenotype of DR6 knockout mice also suggests involvement of DR6 in the regulation of the immune response. Both CD4+ T and B lymphocytes from DR6-/- mice hyperproliferate and grafted DR6-/- T cells trigger accelerated and more severe graft-vs-host disease $(\mathrm{GVHD})^{94-97}$. Despite the pronounced hematopoietic phenotype, discovery of the DR6 ligand came from the neuronal shore. Through functional screening Nikolaev et al. ${ }^{98}$ uncovered that DR6 is required both for death of neuronal bodies as well as for axon pruning and its long-sought ligand is the N-terminal, cleaved-off part of beta-amyloid precursor protein (APP). N-APP-mediated activation of DR6 triggers caspase-3-dependent one apoptosis in cell bodies and caspase-6-dependent in axons. Homologous APLP2, which is expressed on monocytes and dendritic cells, could serve as a ligand for DR6 expressed on activated CD4+ T cells (M. Klima, unpublished data).

\section{Conclusions and perspectives}

The death receptors of the TNFR family are distinguished from the other membrane receptors not only by their specific structural features but mainly by their among membrane receptors very specific function of inducing cell death via both apoptotic and necrotic signaling pathways. The main representatives of pro-death signaling from this group TNFR1, Fas/CD95 and DD-containing TRAIL receptors in the initial stages of pro-apoptotic signaling form multiprotein complexes that serve as activating platforms either for efficient processing of the initiator caspases- 8 and -10 or later on for the transduction of necrotic RIP kinases-mediated signaling. However, the induction of cell death is not the only function of these multitask membrane receptors. Under some circumstance they do induce pro-proliferative and pro-inflammatory response (the main feature of TNFR1-activated signaling) via activation of NFkB and MAP kinases pathways. Unique tumor cells-biased attribute of TRAIL-induced apoptosis is at the presence being exploited therapeutically, and sparks a hope for more efficient and targeted tumor therapy. However, despite significant accumulation of knowledge about the signaling pathways activated by these receptors and their physiological outcomes we still miss important data about regulation of their signaling or their communication with other signaling pathways and 
thus many of these secrets just "eagerly" wait for being, hopefully in a near future, uncovered.

Abbreviations: TRAIL - TNFa-Related ApoptosisInducing Ligand; RIP1 - Receptor Interacting Protein 1; TRAF2 - TNF Receptor Associated Factor 2; IKK - IkB Kinase, FADD - Fas-Associated Death Domain; IAP - Inhibitor of Apoptosis Protein; TRADD - TNF $\alpha$ Receptor Associated-protein with Death Domain, NEMO - NFkB Essential Modulator; zVADfmk - benzoyloxycarbonyl-Val-Ala-Asp(OMe)-fluoromethylketon; ROS Reactive Oxygene Species; NGF - Neural Growth Factor

\section{ACKNOWLEDGEMENTS}

This study was supported by the Center of Molecular and Cellular Imunology (1M6837805001) and the grant KAN200520703 (AVCR).

\section{REFERENCES}

1. Croft M. The role of TNF superfamily members in T-cell function and diseases. Nat Rev Immunol 2009; 9: 271-85

2. Locksley RM, Killeen $\mathrm{N}$ and Lenardo MJ. The TNF and TNF receptor superfamilies: integrating mammalian biology. Cell 2001; 104: 487-501

3. Wilson NS, Dixit V and Ashkenazi A. Death receptor signal transducers: nodes of coordination in immune signaling networks. Nat Immunol 2009; 10: 348-55

4. Carswell EA, Old LJ, Kassel RL, Green S, Fiore N and Williamson B. An endotoxin-induced serum factor that causes necrosis of tumors. Proc Natl Acad Sci U S A 1975; 72: 3666-70

5. Pennica D, Hayflick JS, Bringman TS, Palladino MA and Goeddel DV. Cloning and expression in Escherichia coli of the cDNA for murine tumor necrosis factor. Proc Natl Acad Sci U S A 1985; 82: 6060-4

6. Black RA, Rauch CT, Kozlosky CJ, Peschon JJ, Slack JL, Wolfson $\mathrm{MF}$, et al. A metalloproteinase disintegrin that releases tumournecrosis factor-alpha from cells. Nature 1997; 385: 729-33

7. Tang P, Hung MC and Klostergaard J. Human pro-tumor necrosis factor is a homotrimer. Biochemistry 1996; 35: 8216-25

8. Chan FK, Chun HJ, Zheng L, Siegel RM, Bui KL and Lenardo MJ. A domain in TNF receptors that mediates ligand-independent receptor assembly and signaling. Science 2000; 288: 2351-4

9. Chan FK. Three is better than one: pre-ligand receptor assembly in the regulation of TNF receptor signaling. Cytokine 2007; 37: 101-7

10. Cottin V, Doan JE and Riches DW. Restricted localization of the TNF receptor CD120a to lipid rafts: a novel role for the death domain. J Immunol 2002; 168: 4095-102

11. Legler DF, Micheau O, Doucey MA, Tschopp J and Bron C. Recruitment of TNF receptor 1 to lipid rafts is essential for TNFalpha-mediated NF-kappaB activation. Immunity 2003; 18: 655-64

12. Fujita KI and Srinivasula SM. Ubiquitination and TNFR1 Signaling. Results Probl Cell Differ 2009;

13. Wertz IE and Dixit VM. Ubiquitin-mediated regulation of TNFR1 signaling. Cytokine Growth Factor Rev 2008; 19: 313-24

14. Lee TH, Shank J, Cusson N and Kelliher MA. The kinase activity of Rip1 is not required for tumor necrosis factor-alpha-induced IkappaB kinase or $\mathrm{p} 38 \mathrm{MAP}$ kinase activation or for the ubiquitination of Rip1 by Traf2. J Biol Chem 2004; 279: 33185-91

15. Mahoney DJ, Cheung HH, Mrad RL, Plenchette S, Simard C, Enwere E, et al. Both cIAP1 and cIAP2 regulate TNFalphamediated NF-kappaB activation. Proc Natl Acad Sci U S A 2008; 105: $11778-83$
16. Varfolomeev E, Goncharov T, Fedorova AV, Dynek JN, Zobel K, Deshayes K, et al. c-IAP1 and c-IAP2 are critical mediators of tumor necrosis factor alpha (TNFalpha)-induced NF-kappaB activation. J Biol Chem 2008; 283: 24295-9

17. Tada K, Okazaki T, Sakon S, Kobarai T, Kurosawa K, Yamaoka S, et al. Critical roles of TRAF2 and TRAF5 in tumor necrosis factorinduced NF-kappa B activation and protection from cell death. J Biol Chem 2001; 276: 36530-4

18. Yeh WC, Shahinian A, Speiser D, Kraunus J, Billia F, Wakeham A, et al. Early lethality, functional NF-kappaB activation, and increased sensitivity to TNF-induced cell death in TRAF2-deficient mice. Immunity 1997; 7: 715-25

19. Ea CK, Deng L, Xia ZP, Pineda G and Chen ZJ. Activation of IKK by TNFalpha requires site-specific ubiquitination of RIP1 and polyubiquitin binding by NEMO. Mol Cell 2006; 22: 245-57

20. Wu CJ, Conze DB, Li T, Srinivasula SM and Ashwell JD. Sensing of Lys 63-linked polyubiquitination by NEMO is a key event in NF-kappaB activation [corrected]. Nat Cell Biol 2006; 8: 398-406

21. Blonska M, Shambharkar PB, Kobayashi M, Zhang D, Sakurai H, $\mathrm{Su} \mathrm{B}$, et al. TAK1 is recruited to the tumor necrosis factor-alpha (TNF-alpha) receptor 1 complex in a receptor-interacting protein (RIP)-dependent manner and cooperates with MEKK3 leading to NF-kappaB activation. J Biol Chem 2005; 280: 43056-63

22. Karin $M$ and Ben-Neriah Y. Phosphorylation meets ubiquitination: the control of NF-[kappa]B activity. Annu Rev Immunol 2000; 18: 621-63

23. Lee EG, Boone DL, Chai S, Libby SL, Chien M, Lodolce JP, et al. Failure to regulate TNF-induced NF-kappaB and cell death responses in A20-deficient mice. Science 2000; 289: 2350-4

24. Shembade N, Harhaj NS, Liebl DJ and Harhaj EW. Essential role for TAX1BP1 in the termination of TNF-alpha-, IL-1- and LPSmediated NF-kappaB and JNK signaling. Embo J 2007; 26: 3910-22

25. Shembade N, Harhaj NS, Parvatiyar K, Copeland NG, Jenkins NA, Matesic LE, et al. The E3 ligase Itch negatively regulates inflammatory signaling pathways by controlling the function of the ubiquitin-editing enzyme A20. Nat Immunol 2008; 9: 254-62

26. Shembade N, Parvatiyar K, Harhaj NS and Harhaj EW. The ubiquitin-editing enzyme A20 requires RNF11 to downregulate NFkappaB signalling. Embo J 2009; 28: 513-22

27. Habelhah H, Frew IJ, Laine A, Janes PW, Relaix F, Sassoon D, et al. Stress-induced decrease in TRAF2 stability is mediated by Siah2. Embo J 2002; 21: 5756-65

28. Nakayama K, Frew IJ, Hagensen M, Skals M, Habelhah H, Bhoumik A, et al. Siah2 regulates stability of prolyl-hydroxylases, controls HIF1alpha abundance, and modulates physiological responses to hypoxia. Cell 2004; 117: 941-52

29. McDonald ER, 3rd and El-Deiry WS. Suppression of caspase-8and -10-associated RING proteins results in sensitization to death ligands and inhibition of tumor cell growth. Proc Natl Acad Sci U S A 2004; 101: 6170-5

30. Liao W, Xiao Q, Tchikov V, Fujita K, Yang W, Wincovitch S, et al. CARP-2 is an endosome-associated ubiquitin ligase for RIP and regulates TNF-induced NF-kappaB activation. Curr Biol 2008; 18: 641-9

31. Brummelkamp TR, Nijman SM, Dirac AM and Bernards R. Loss of the cylindromatosis tumour suppressor inhibits apoptosis by activating NF-kappaB. Nature 2003; 424: 797-801

32. Jono H, Lim JH, Chen LF, Xu H, Trompouki E, Pan ZK, et al. NF-kappaB is essential for induction of CYLD, the negative regulator of NF-kappaB: evidence for a novel inducible autoregulatory feedback pathway. J Biol Chem 2004; 279: 36171-4

33. Kovalenko A, Chable-Bessia C, Cantarella G, Israel A, Wallach D and Courtois G. The tumour suppressor CYLD negatively regulates NF-kappaB signalling by deubiquitination. Nature 2003; 424: 801-5

34. Micheau O and Tschopp J. Induction of TNF receptor I-mediated apoptosis via two sequential signaling complexes. Cell 2003; 114: $181-90$

35. Wang L, Du F and Wang X. TNF-alpha induces two distinct caspase-8 activation pathways. Cell 2008; 133: 693-703

36. Schutze S, Tchikov V and Schneider-Brachert W. Regulation of TNFR1 and CD95 signalling by receptor compartmentalization. Nat Rev Mol Cell Biol 2008; 9: 655-62 
37. Festjens N, Vanden Berghe T, Cornelis S and Vandenabeele P. RIP1, a kinase on the crossroads of a cell's decision to live or die. Cell Death Differ 2007; 14: 400-10

38. Cho YS, Challa S, Moquin D, Genga R, Ray TD, Guildford M, et al. Phosphorylation-driven assembly of the RIP1-RIP3 complex regulates programmed necrosis and virus-induced inflammation. Cell 2009; 137: 1112-23

39. Degterev A, Hitomi J, Germscheid M, Ch'en IL, Korkina O, Teng $\mathrm{X}$, et al. Identification of RIP1 kinase as a specific cellular target of necrostatins. Nat Chem Biol 2008; 4: 313-21

40. Degterev A, Huang Z, Boyce M, Li Y, Jagtap P, Mizushima N, et al. Chemical inhibitor of nonapoptotic cell death with therapeutic potential for ischemic brain injury. Nat Chem Biol 2005; 1: 112-9

41. Hitomi J, Christofferson DE, Ng A, Yao J, Degterev A, Xavier RJ, et al. Identification of a molecular signaling network that regulates a cellular necrotic cell death pathway. Cell 2008; 135: 1311-23

42. Feng S, Yang Y, Mei Y, Ma L, Zhu DE, Hoti N, et al. Cleavage of RIP3 inactivates its caspase-independent apoptosis pathway by removal of kinase domain. Cell Signal 2007; 19: 2056-67

43. He S, Wang L, Miao L, Wang T, Du F, Zhao L, et al. Receptor interacting protein kinase-3 determines cellular necrotic response to TNF-alpha. Cell 2009; 137: 1100-11

44. Zhang DW, Shao J, Lin J, Zhang N, Lu BJ, Lin SC, et al. RIP3, an energy metabolism regulator that switches TNF-induced cell death from apoptosis to necrosis. Science 2009; 325: 332-6

45. Itoh N, Yonehara S, Ishii A, Yonehara M, Mizushima S, Sameshima $\mathrm{M}$, et al. The polypeptide encoded by the cDNA for human cell surface antigen Fas can mediate apoptosis. Cell 1991; 66: 233-43

46. Pan G, O'Rourke K, Chinnaiyan AM, Gentz R, Ebner R, Ni J, et al. The receptor for the cytotoxic ligand TRAIL. Science 1997; 276: 111-3

47. Walczak H, Degli-Esposti MA, Johnson RS, Smolak PJ, Waugh JY, Boiani N, et al. TRAIL-R2: a novel apoptosis-mediating receptor for TRAIL. Embo J 1997; 16: 5386-97

48. Wiley SR, Schooley K, Smolak PJ, Din WS, Huang CP, Nicholl $\mathrm{JK}$, et al. Identification and characterization of a new member of the TNF family that induces apoptosis. Immunity 1995; 3: 673-82

49. Pitti RM, Marsters SA, Lawrence DA, Roy M, Kischkel FC, Dowd $\mathrm{P}$, et al. Genomic amplification of a decoy receptor for Fas ligand in lung and colon cancer. Nature 1998; 396: 699-703

50. Schaefer U, Voloshanenko O, Willen D and Walczak H. TRAIL: a multifunctional cytokine. Front Biosci 2007; 12: 3813-24

51. Peter ME. The flip side of FLIP. Biochem J 2004; 382: e1-3

52. Feig C, Tchikov V, Schutze S and Peter ME. Palmitoylation of CD95 facilitates formation of SDS-stable receptor aggregates that initiate apoptosis signaling. Embo J 2007; 26: 221-31

53. Kohlhaas SL, Craxton A, Sun XM, Pinkoski MJ and Cohen GM. Receptor-mediated endocytosis is not required for tumor necrosis factor-related apoptosis-inducing ligand (TRAIL)-induced apoptosis. J Biol Chem 2007; 282: 12831-41

54. Chakrabandhu K, Herincs Z, Huault S, Dost B, Peng L, Conchonaud F, et al. Palmitoylation is required for efficient Fas cell death signaling. Embo J 2007; 26: 209-20

55. Wagner KW, Punnoose EA, Januario T, Lawrence DA, Pitti RM, Lancaster K, et al. Death-receptor O-glycosylation controls tumorcell sensitivity to the proapoptotic ligand Apo2L/TRAIL. Nat Med 2007; 13: 1070-7

56. Barnhart BC, Alappat EC and Peter ME. The CD95 type I/type II model. Semin Immunol 2003; 15: 185-93

57. Jost PJ, Grabow S, Gray D, McKenzie MD, Nachbur U, Huang DC, et al. XIAP discriminates between type I and type II FASinduced apoptosis. Nature 2009; 460: 1035-9

58. Ozoren N and El-Deiry WS. Defining characteristics of Types I and II apoptotic cells in response to TRAIL. Neoplasia 2002; 4: 551-7

59. Schmitz I, Walczak H, Krammer PH and Peter ME. Differences between CD95 type I and II cells detected with the CD95 ligand. Cell Death Differ 1999; 6: 821-2

60. Yin XM. Bid, a critical mediator for apoptosis induced by the activation of Fas/TNF-R1 death receptors in hepatocytes. J Mol Med 2000; 78: 203-11

61. Zha J, Weiler S, Oh KJ, Wei MC and Korsmeyer SJ. Post- translational N-myristoylation of BID as a molecular switch for targeting mitochondria and apoptosis. Science 2000; 290: 1761-5

62. Billen LP, Shamas-Din A and Andrews DW. Bid: a Bax-like BH3 protein. Oncogene 2008; 27 Suppl 1: S93-104

63. Ott M, Norberg E, Zhivotovsky B and Orrenius S. Mitochondrial targeting of tBid/Bax: a role for the TOM complex? Cell Death Differ 2009; 16: 1075-82

64. Roucou X, Montessuit S, Antonsson B and Martinou JC. Bax oligomerization in mitochondrial membranes requires $\mathrm{tBid}$ (caspase8-cleaved Bid) and a mitochondrial protein. Biochem J 2002; 368: 915-21

65. Schafer B, Quispe J, Choudhary V, Chipuk JE, Ajero TG, Du H, et al. Mitochondrial outer membrane proteins assist Bid in Baxmediated lipidic pore formation. Mol Biol Cell 2009; 20: 2276-85

66. Kroemer G, Galluzzi L and Brenner C. Mitochondrial membrane permeabilization in cell death. Physiol Rev 2007; 87: 99-163

67. Gonzalvez F, Schug ZT, Houtkooper RH, MacKenzie ED, Brooks DG, Wanders RJ, et al. Cardiolipin provides an essential activating platform for caspase-8 on mitochondria. J Cell Biol 2008; 183: 681-96

68. Falschlehner C, Schaefer U and Walczak H. Following TRAIL's path in the immune system. Immunology 2009; 127: 145-54

69. Strasser A, Jost PJ and Nagata S. The many roles of FAS receptor signaling in the immune system. Immunity 2009; 30: 180-92

70. Bouillet P and O'Reilly LA. CD95, BIM and T cell homeostasis. Nat Rev Immunol 2009; 9: 514-9

71. Grosse-Wilde A, Voloshanenko O, Bailey SL, Longton GM, Schaefer U, Csernok AI, et al. TRAIL-R deficiency in mice enhances lymph node metastasis without affecting primary tumor development. J Clin Invest 2008; 118: 100-10

72. Janssen EM, Droin NM, Lemmens EE, Pinkoski MJ, Bensinger SJ, Ehst BD, et al. CD4+ T-cell help controls CD8+ T-cell memory via TRAIL-mediated activation-induced cell death. Nature 2005; 434: 88-93

73. Holler N, Zaru R, Micheau O, Thome M, Attinger A, Valitutti S, et al. Fas triggers an alternative, caspase-8-independent cell death pathway using the kinase RIP as effector molecule. Nat Immunol 2000; 1: 489-95

74. Strauss G, Lindquist JA, Arhel N, Felder E, Karl S, Haas TL, et al. CD95 co-stimulation blocks activation of naive $\mathrm{T}$ cells by inhibiting T cell receptor signaling. J Exp Med 2009; 206: 1379-93

75. Walczak H, Miller RE, Ariail K, Gliniak B, Griffith TS, Kubin M, et al. Tumoricidal activity of tumor necrosis factor-related apoptosis-inducing ligand in vivo. Nat Med 1999; 5: 157-63

76. Bellail AC, Qi L, Mulligan P, Chhabra V and Hao C. TRAIL agonists on clinical trials for cancer therapy: the promises and the challenges. Rev Recent Clin Trials 2009; 4: 34-41

77. Papenfuss K, Cordier SM and Walczak H. Death receptors as targets for anti-cancer therapy. J Cell Mol Med 2008; 12: 2566-85

78. Headon DJ and Overbeek PA. Involvement of a novel Tnf receptor homologue in hair follicle induction. Nat Genet 1999; 22: 370-4

79. Gaide $\mathrm{O}$ and Schneider P. Permanent correction of an inherited ectodermal dysplasia with recombinant EDA. Nat Med 2003; 9: 614-8

80. Trompouki E, Hatzivassiliou E, Tsichritzis T, Farmer H, Ashworth A and Mosialos G. CYLD is a deubiquitinating enzyme that negatively regulates NF-kappaB activation by TNFR family members. Nature 2003; 424: 793-6

81. Yan M, Zhang Z, Brady JR, Schilbach S, Fairbrother WJ and Dixit VM. Identification of a novel death domain-containing adaptor molecule for ectodysplasin-A receptor that is mutated in crinkled mice. Curr Biol 2002; 12: 409-13

82. Chen Y, Zeng J, Chen Y, Wang X, Yao G, Wang W, et al. Multiple roles of the p75 neurotrophin receptor in the nervous system. J Int Med Res 2009; 37: 281-8

83. Teng KK and Hempstead BL. Neurotrophins and their receptors: signaling trios in complex biological systems. Cell Mol Life Sci 2004; 61: 35-48

84. Casaccia-Bonnefil P, Carter BD, Dobrowsky RT and Chao MV. Death of oligodendrocytes mediated by the interaction of nerve growth factor with its receptor p75. Nature 1996; 383: 716-9 
85. Volosin M, Trotter C, Cragnolini A, Kenchappa RS, Light M, Hempstead BL, et al. Induction of proneurotrophins and activation of p75NTR-mediated apoptosis via neurotrophin receptor-interacting factor in hippocampal neurons after seizures. J Neurosci 2008; 28: $9870-9$

86. Chinnaiyan AM, O'Rourke K, Yu GL, Lyons RH, Garg M, Duan DR, et al. Signal transduction by DR3, a death domain-containing receptor related to TNFR-1 and CD95. Science 1996; 274: 990-2

87. Pan G, Bauer JH, Haridas V, Wang S, Liu D, Yu G, et al. Identification and functional characterization of DR6, a novel death domain-containing TNF receptor. FEBS Lett 1998; 431: $351-6$

88. Migone TS, Zhang J, Luo X, Zhuang L, Chen C, Hu B, et al. TL1A is a TNF-like ligand for DR3 and TR6/DcR3 and functions as a T cell costimulator. Immunity 2002; 16: 479-92

89. Fang L, Adkins B, Deyev V and Podack ER. Essential role of TNF receptor superfamily 25 (TNFRSF25) in the development of allergic lung inflammation. J Exp Med 2008; 205: 1037-48

90. Meylan F, Davidson TS, Kahle E, Kinder M, Acharya K, Jankovic $\mathrm{D}$, et al. The TNF-family receptor DR3 is essential for diverse T cell-mediated inflammatory diseases. Immunity 2008; 29: 79-89

91. Al-Lamki RS, Wang J, Tolkovsky AM, Bradley JA, Griffin JL, Thiru $\mathrm{S}$, et al. TL1A both promotes and protects from renal inflammation and injury. J Am Soc Nephrol 2008; 19: 953-60
92. Bull MJ, Williams AS, Mecklenburgh Z, Calder CJ, Twohig JP, Elford C, et al. The Death Receptor 3-TNF-like protein 1A pathway drives adverse bone pathology in inflammatory arthritis. J Exp Med 2008; 205: 2457-64

93. Klima M, Zajedova J, Doubravska L and Andera L. Functional analysis of the posttranslational modifications of the Death Receptor 6. Biochim Biophys Acta 2009;

94. Liu J, Heuer JG, Na S, Galbreath E, Zhang T, Yang DD, et al. Accelerated onset and increased severity of acute graft-versus-host disease following adoptive transfer of DR6-deficient T cells. J Immunol 2002; 169: 3993-8

95. Liu J, Na S, Glasebrook A, Fox N, Solenberg PJ, Zhang Q, et al. Enhanced CD4+ T cell proliferation and Th2 cytokine production in DR6-deficient mice. Immunity 2001; 15: 23-34

96. Schmidt CS, Liu J, Zhang T, Song HY, Sandusky G, Mintze K, et al. Enhanced B cell expansion, survival, and humoral responses by targeting death receptor 6. J Exp Med 2003; 197: 51-62

97. Zhao H, Yan M, Wang H, Erickson S, Grewal IS and Dixit VM. Impaired c-Jun amino terminal kinase activity and T cell differentiation in death receptor 6-deficient mice. J Exp Med 2001; 194: 1441-8

98. Nikolaev A, McLaughlin T, O'Leary DD and Tessier-Lavigne M. APP binds DR6 to trigger axon pruning and neuron death via distinct caspases. Nature 2009; 457: 981-9 